\title{
O CONTROLE INTERNO COMO INSTRUMENTO AUXILIAR NA GESTÃO MUNICIPAL: UM ESTUDO DE CASO NO MUNICÍPIO DE CONFRESA-MT
}

\author{
José Pereira Cordão ${ }^{1}$ \\ Pâmela Gabriela Ramos ${ }^{2}$
}

\section{RESUMO}

Em virtude de inúmeras mudanças ocorridas na administração pública, é cada vez mais necessário obter instrumentos que auxiliem os gestores. As exigências do novo modelo gerencial de administração trouxe uma forma mais transparente e ética de gestão dos recursos públicos. Inúmeros escândalos denegriram a imagem dos órgãos públicos e para minimizar esses impactos e garantir a excelência no gasto público, os Tribunais de Contas exigiram um controlador nas prefeituras. Diante desse contexto foi desenhado o objetivo da pesquisa, que consistiu em analisar a visão dos gestores sobre como o Controle Interno os têm auxiliado. Trata-se de uma pesquisa quantitativo-qualitativa, caracterizada por estudo de caso, tendo como instrumento para coleta de dados o uso de questionários e as análises dos mesmos foram feitas através da elaboração de gráficos e a análise de conteúdo, proposta por Bardin (1977).

Palavras-chave: Controle Interno. Gestores. Melhorias.

\section{INTRODUÇÃO}

Muito se têm discutido acerca da efetiva implementação do Controle Interno na administração pública, por um lado a exigência e fiscalização dos Tribunais de Contas, visando garantir transparência e credibilidade das ações desenvolvidas na esfera Federal, Estadual e Municipal, na outra vertente as dificuldades desses entes em encontrar profissionais aptos a desenvolver, auxiliar e direcionar as ações dos gestores no que se refere à excelência do gasto público.

A implantação do Sistema de Controle Interno é considerado atualmente um instrumento de suma importância. De acordo como Tribunal de Contas de Mato Grosso (TCE-MT, 2007) o Controle Interno tem como objetivo o fiel cumprimento à legislação e preservação dos bens e recursos públicos. Além disso, o Controle Interno deve ser claro para que consiga alcançar um nível satisfatório de resultado, transmitindo aos cidadãos a certeza de que os recursos públicos estão sendo bem aplicados, demonstrando maior transparência nos atos dos gestores públicos, garantindo a fiscalização contábil, financeira, orçamentária, operacional e patrimonial e avaliação dos resultados.

\footnotetext{
${ }^{1}$ Médico Veterinário, atualmente secretário de Planejamento da prefeitura de Confresa-MT. E-mail: jpcordao@ hotmail.com

${ }^{2}$ Pós-Graduanda em Gestão Pública, Docente na Universidade do Estado de Mato Grosso. Rua São José, nº 02, Cavalhada II. CEP: 78200-000. E-mail: pamela.tutoriauab@ gmail.com.
} 
Diante do exposto e da temática da inserção do Controle Interno na gestão municipal, considerando uma prefeitura onde este já fora implantado, surge à problemática: a ferramenta de controle interno tem contribuído na gestão e tomada de decisões dos gestores do Município de Confresa- MT?

Partindo deste pressuposto, a pesquisa apresenta o seguinte objetivo; analisar como o Controle Interno tem auxiliado os gestores da prefeitura de Confresa - MT.

Esta pesquisa delimita-se à análise da visão dos gestores sobre como o Controle Interno os auxiliam.

\section{CONTROLE INTERNO}

Uma série de fatores como a globalização, tecnologia e competitividade fez emergir nas empresas a necessidade de um controle efetivo que proporcionasse aos gestores suporte para tomada de decisões. A finalidade do controle interno é permitir que a empresa mantenhase orientada para os seus objetivos, atingindo o lucro.Peleias (2003) diz que:

Controle interno é um conjunto de normas, procedimentos, instrumentos e ações adotadas de forma sistemática pelas empresas, que devem estar em constante evolução, assegurando atingir os resultados conforme objetivos pré-estabelecidos, protegendo o patrimônio e garantindo transparência às operações. PELEIAS (2003, p.04)

Attie (2007) acrescenta que:

O controle interno compreende o plano de organização e o conjunto coordenado de métodos e medidas, adotados pela empresa, para proteger o seu patrimônio, verificar a exatidão e a fidedignidade de seus dados contábeis, promover aeficiência operacional e encorajar a adesão à política traçada pela administração. (ATTIE, 2007, p. 182)

Conforme visto, o controle interno auxilia as empresa, direcionando-as à consecução de seus objetivos de forma correta, porém muitas pessoas ainda confundem o conceito de controle interno e auditoria interna. Segundo Queiroz (2009) o controle interno é responsável pelos procedimentos e medidas de redução de falhas, acompanhamento e execução das atividades em caráter opinativo, preventivo ou corretivo, garantindo a fidelidade das informações geradas, fornecendo subsídios para a tomada de decisão, já a auditoria interna é responsável pela revisão, avaliação e acompanhamento dos controles internos, verificando o melhor cumprimento das políticas traçadas pela administração. 
Apesar de parecerem sistemas distintos ou fiscalizadores, são complementares entre si, para Cruz e Glock (2006):

\begin{abstract}
A verificação da qualidade do Sistema interno como um todo, ou seja, a aferição, através de uma revisão e avaliação regular e independente de como funcionam os procedimentos de controle existentes nas atividades contábeis, financeiras administrativas, operacionais e técnicas, em todas as áreas da organização é executada através da atividade de auditoria que, por ser exercida internamente à organização, é denominada de Auditoria Interna. CRUZ e GLOCK (2006, p. 27).
\end{abstract}

Percebe- se diante do exposto que o Sistema de Controle Interno tem a mesma finalidade que a Auditoria Interna, só que ao invés de ser realizada em prazos determinado, o Controle Interno age diariamente dentro da organização.

\title{
2.1 CONTROLE INTERNO NA ADMINISTRAÇÃO PÚBLICA
}

Diferente das empresas privadas, cuja finalidade é o lucro, e para tal devem observar toda movimentação do mercado, nos órgãos públicos o que existe é a consecução do bem comum, levado a cabo com a utilização de recursos públicos, razão porque impõe claridade, ética e transparência.

O controle interno nos órgãos da administração pública surgiu como meio de transparência e gestão dos recursos, não há uma data específica do seu surgimento, o que se sabe é que os vários casos de corrupção, desvios e fraudes impulsionaram a criação de uma fiscalização intensa e minuciosa em todos os órgãos públicos.

Conforme Araújo (1993), o controle interno na administração pública relaciona-se ao processo de evolução do controle das contas públicas. Para Brito (2009) a Administração Pública por meio do controle interno, em todos os níveis (Federal, Estadual e Municipal) enfrenta o desafio de ser "olhos dos cidadãos" no que se refere à correta aplicação dos recursos públicos.

Para Leite e Martins (2011), o sistema de controle interno é um instrumento que, corretamente empregado é um importante elemento que orienta os gestores nas tomadas de decisões, além de contribuir para colocar em prática os princípios constitucionais da Legalidade, Impessoalidade, Moralidade, Publicidade e eficiência do ato administrativo, 
garantindo proteção ao patrimônio público e combate preventivo aos Atos de Improbidade Administrativa.

O Tribunal de Contas de Mato Grosso (TCE-MT) ressalta a importância do Controle Interno público, dizendo que este constitui o tripé do controle no âmbito da Administração Pública (os outros dois são o controle social e o controle externo). Souza (2008) diz que:

Controle Interno é o instrumento obrigatório que auxilia na Gestão Pública e atua de forma preventiva na detecção de irregularidades, conferindo maior eficácia, eficiência e economicidade aos gastos públicos e dando mais transparência na aplicação dos recursos públicos. (SOUZA 2008, p. 14)

Através do controle interno, a fiscalização e detecção de falhas e erros são alcançadas de forma mais eficaz. Quando comparada a auditoria, que apresentava um custo elevado, se chegou à conclusão de que a implantação do controle interno seria a alternativa mais viável (em termos de valores e efetividade) para auxiliar a gestão e garantir transparência na aplicação dos recursos públicos.

A base legal da implantação do controle interno na administração pública encontra-se no art. 70 da Constituição Federal 1988:

A fiscalização contábil, financeira orçamentária, operacional e patrimonial da União e das entidades da administração direta e indireta, quanto à legalidade, legitimidade, economicidade, aplicação das subvenções e renuncia de receitas, será exercida pelo Congresso Nacional, mediante controle externo, e pelo sistema de controle interno de cada poder.

No entanto, conforme destaca Souza (2008), até a publicação da Lei de Responsabilidade Fiscal, embora presente na Constituição Federal de 1988 e já previsto desde a Lei n 4320/64, a Administração Pública não dispensava a devida atenção para o Controle Interno. A autora ainda acrescenta que somente com o advento da LRF em 2000 que a administração pública começou a evoluir em termos de cultura quanto à gestão (orçamentária, patrimonial e financeira) e utilização das diversas modalidades de controle.

A LRF foi criada com o intuito de coibir o desperdício de recursos públicos, aumentar a fiscalização e a transparência:

$\S 1^{\circ}$ A responsabilidade na gestão fiscal pressupõe a ação planejada e transparente, em que se previnem riscos e corrigem desvios capazes de afetar o equilíbrio das contas públicas, mediante o cumprimento de metas de resultados entre receitas e despesas e a obediência a limites e condições no que tange a renúncia de receita, geração de despesas 
com pessoal, da seguridade social e outras, dívidas consolidada e mobiliária, operações de crédito, inclusive por antecipação de receita, concessão de garantia e inscrição em Restos a Pagar.

Vislumbra-se, portanto, que uma das finalidades da LRF é a busca do equilíbrio atual entre o valor das despesas a serem realizadas com as ações governamentais de toda natureza e as receitas disponíveis para essa finalidade, prevenindoos futuros desequilíbrios fiscais dos governos, por meio da limitação de gastos públicos permanentes. Diante das limitações impostas percebe-se que a promulgação da LRF visava um maior controle dos gastos públicos.

Em seu art. 59, a LRF aborda diretamente o tema do controle interno, nos seguintes termos:

Art. 59. O Poder Legislativo, diretamente ou com o auxílio dos Tribunais deContas, e o sistema de controle interno de cada Poder e do Ministério Público, fiscalizarão o cumprimento das normas desta Lei Complementar, com ênfase no que se refere a:

I - Atendimento das metas estabelecidas na lei de diretrizes orçamentárias;

II - Limites e condições para realização de operações de crédito e inscrição em Restos a Pagar;

III - Medidas adotadas para retorno da despesa total com o pessoal a respectivo limite, nos termos dos art. 22 e 23;

IV - Providências tomadas, conforme o disposto no art. 31, para recondução dos montantes das dívidas consolidadas e mobiliária aos respectivos limites; V - Destinação de recursos obtidos com a alienação de ativos, tendo em vista as restrições constitucionais e as desta Lei Complementar;

VI - Cumprimento do limite de gastos totais dos legislativos municipais,quando houver.

Percebe-se que a lei acima citada está direcionada aos diversos entes da administração pública, cada um contendo as especificidades que devem ser observadas para um bom desempenho e alcance de suas finalidades.

A seguir será abordado o controle interno na gestão municipal, foco desse estudo.

\subsection{CONTROLE INTERNO NA GESTÃO PÚBLICA MUNICIPAL}

O controle interno, conforme visto deve ser instituído em todas as esferas do governo. A preocupação de instituí-lo também na gestão municipal, é que este ente, conforme art. 30 da Constituição Federal de 1988 (CF/88) possui uma série de atribuições que devem ser realizadas de maneira ética e transparente, cita-se a arrecadação e aplicação dos tributos de 
sua competência, prestação de serviços de saúde, dentre outras. Damascena e Souza (2011) ressaltam que:

O controle interno na administração pública municipal surgiu da necessidade de assegurar aos gestores o cumprimento das leis, normas e políticas vigentes, através do estabelecimento de mecanismos de controle que possibilitem informações à sociedade, impedindo a ocorrência de fraudes e desperdícios, servindo de instrumento que visa garantir a efetividade, a produtividade, a economicidade e a rapidez na prestação do serviço público. (DAMASCENA E SOUZA 2011, p. 02)

Cabe ressaltar que o controle interno surgiu fundamentalmente como meio de auxiliar e direcionar as ações de garantir o cumprimento das normativas legais. Uma pesquisa realizada pelo TCE-PR apontou os 10 (dez) maiores motivos de não aprovação das contas dos municípios até o ano de 2008, dentre elas, os mais comuns são: a ausência de documentos, realização de despesa sem licitação, prestação de contas realizadas fora do prazo, divergência de saldos, entre outros; e garante que o controle interno seria a única alternativa de direcionar e orientar os gestores sobre como proceder diante de cada especificidade que deve ser observada.

As formas do controle interno, conforme Cruz e Glock (2006) são: o Controle Interno Contábil: cujo objeto é a salvaguarda dos bens, direitos, obrigações e a fidedignidade dos registros financeiros e o Controle Interno Administrativo: cujo objeto é garantir a eficiência operacional, o cumprimento dos aspectos legais e a observância das políticas, diretrizes, normas e instruções.

O TCE-PB (2009) elenca os seguintes tópicos como fatores que garantem a importância dos controles internos não só nos municípios, mas na área pública:

I. Garantir a "memória" do órgão que, não obstante a constante troca de seus gestores, decorrente de pleitos políticos, deve ter garantida a continuidade da sua existência;

II. Garantir a padronização dos procedimentos de controle, independente da manutenção ou troca dos servidores que o operacionalizam, bem como dos gestores aos quais as informações são prestadas;

III. Conhecer, a qualquer tempo, a instituição - receitas, despesas, resultados históricos, estrutura administrativa, pessoal, patrimônio etc.;

IV. Acompanhamento, em tempo real, da programação estabelecida nos instrumentos de planejamento (Planos Plurianuais - PPA, Lei de Diretrizes Orçamentárias - LDO, Leis Orçamentárias Anuais - LOA, Metas Bimestrais de Arrecadação - MBA e Cronogramas Mensais de Desembolso - CMD);

V. Constante busca de equilíbrio nas contas públicas;

VI. Exigência da correta aplicação administrativa e financeira dos recursos públicos; 
VII. Evitar fraudes, desvios e erros cometidos por gestores e servidores em geral;

VIII. Busca do atendimento de metas de aplicação de percentuais mínimos e máximos impostos pela legislação em vigor.

A eficiência da gestão pública está diretamente relacionada a uma série de fatores que vão desde a observância das leis até um direcionamento estratégico. Para atingir esse nível de eficiência o Controle Interno se destaca como a melhor alternativa, pois acompanha e direciona diariamente as ações dos gestores.

Damascena e Souza (2011) observam que, o controle interno além de garantir o desempenho correto das funções exercidas conforme a legislação em vigor fornece subsídios para que o controle externo seja exercido. Meirelles (2006) esclarece que:

A fiscalização financeira e orçamentária no âmbito municipal realiza-se mediante controle externo da Câmara de Vereadores, com o auxílio do Tribunal de Contas dos Estados ou do Município ou dos Conselhos ou Tribunais de Contas dos Municípios, onde houver, e controle interno do Executivo Municipal. (MEIRELLES 2006, p. 293)

Percebe-se um olhar especial para garantir a fiscalização e emprego dos recursos públicos, neste contexto o controle interno, independente da esfera do poder, torna-se parte fundamental na administração para o gestor público. Havendo um sistema de controle interno bem implantado e rigoroso quanto às normativas e as aplicações das ações dos gestores, dificilmente ocorrerão fraudes e corrupção no sistema de gestão pública.

\section{RESULTADOS E DISCUSSÕES}

Visando responder o objetivo proposto, foi aplicado um questionário contendo 10 (dez) perguntas aos gestores (secretários e contador). O questionário foi construído de forma semi-estruturada, com questões objetivas e subjetivas na busca de identificar e analisar a visão dos gestores da Prefeitura Municipal de Confresa sobre como o Controle Interno tem os auxiliado. Segundo Beuren (2004):

O questionário é um instrumento de coleta de dados constituído por uma serie ordenada de perguntas que devem ser respondidas por escrito pelo informante, sem a presença do pesquisador. Devem ser claro e limitado em extensão e estar acompanhado de notas que expliquem a natureza da pesquisa e ressaltem a importância e necessidade das respostas, a fim de motivar o informante. BEUREN (2004 p, 130) 
Gil (1999) define o questionário como uma técnica de investigação composta por um número de questões apresentados por escrito as pessoas, com objetivo o conhecimento de suas opiniões.A análise das mesmas foi feita como seguem.

Participaram da pesquisa os secretários de Saúde, Agricultura e Meio Ambiente, Planejamento, Educação, Administração, Obras, Finanças, Assistência Social e a contadora da prefeitura. A primeira pergunta refere-se à identificação desse gestor, ou seja, a qual secretaria pertence. A prefeitura de Confresa conta atualmente com 8 (oito) secretarias, na qual todos os responsáveis responderam ao questionário.

A primeira pergunta se refereà participação dos gestores na implantação do Controle Interno, nesse quesito a resposta foi unânime, todos responderam que não pelo fato de não serem secretários na época (2007).

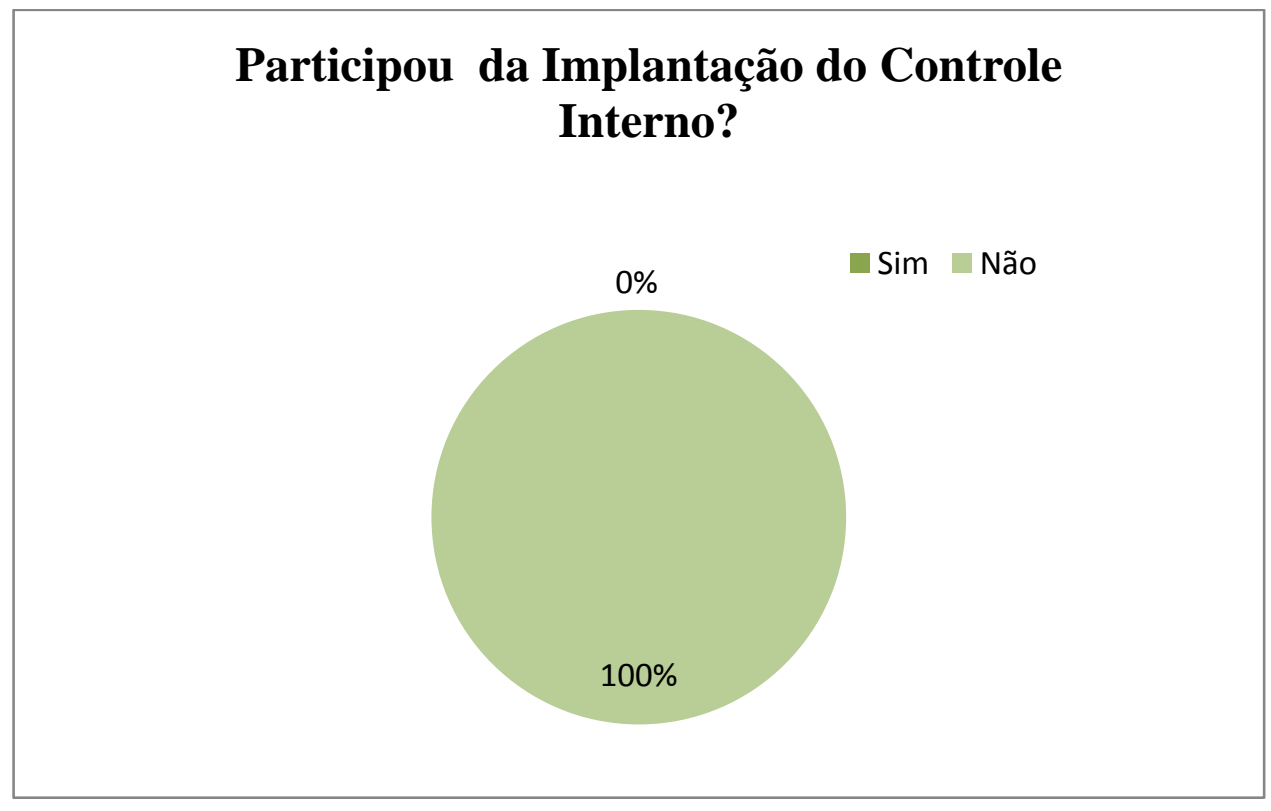

Fonte: elaborado pelos autores

Dessa forma conclui-se que o Controle interno não é algo novo na prefeitura e conforme será abordado mais adiante, o setor já passou pelas fases de evolução e que hoje se encontra apto a auxiliar os gestores.

A segunda pergunta estava diretamente relacionada à primeira, caso os gestores tivessem participado da implantação do Controle Interno indicariam quais as mudanças e melhorias oriundas após a sua implantação no município. Porém devido o fato de que nenhum dos entrevistados atuava nos atuais cargos no ano em questão, a presente pesquisa não pôde comparar essas duas vertentes do antes e pós Controle Interno. 
Posteriormente, seguindo o foco da pesquisa, passou-se a analisar a visão dos gestores sobre como o Controle Interno os auxilia no direcionamento de suas ações. Nesse contexto é primordial saber como é o relacionamento entre gestores e controlador interno.Pelo fato de sermos seres sociáveis, dentre as várias formas de relacionamento (em casa, com os amigos, entre outros) os de trabalho são diferenciados por dois motivos: um é que não escolhemos nossos colegas, chefes, clientes ou parceiros; o outro é que, independentemente do grau de afinidade que temos com as pessoas do ambiente corporativo, precisamos funcionar bem com elas para realizar algo juntos. (Pereira, 2014)

No que concerne ao relacionamento interpessoal, Chiavenato (2005) afirma que:

O ser humano é eminentemente social: ele não vive isolado, mas em continua interação com seus semelhantes. Nas interações humanas, ambas as partes envolvem-se mutuamente, uma influenciando a atitude que a outra irá tomar, e vice-versa. Devido às suas limitações individuais, os seres humanos são obrigados a cooperarem uns com os outros, formando organizações para alcançar objetivos. A organização é um sistema de atividades conscientemente coordenadas de duas ou mais pessoas. A cooperação entre elas é essencial para a existência da organização.(CHIAVENATO, 2005, p.20).

Analisando esse contexto, percebe-se que o relacionamento interpessoal influencia diretamente no ambiente e bom funcionamento do órgão em si. Fortalecer essas bases acarreta em melhorias não só para as interações no trabalho, mas também para as de outras áreas da vida, cita-se o desenvolvimento pessoal.

Quando se trata da relação Controle Interno x Secretarias, necessário se faz um bom relacionamento entre ambos, considerando a posição e papel do controle interno e as necessidades das secretarias quanto ao direcionamento de suas atividades de forma transparente e correta.

Quando questionados sobre a relação dos gestores com o Controlador, todos responderam que há uma boa convivência, respeito mútuo e que na parte profissional há retorno de informações, assim como presteza no atendimento.

Além do fator relacionamento é necessário também verificar se o mesmo está preparado para o cargo, pois ocupa um lugar de staff, onde todos os setores (secretarias e contabilidade), em caso de dúvidas sabem onde e a quem recorrer.

Com o objetivo de verificar a aptidão do controlador, foi perguntado se o mesmo estava apto a realizar suas funções, onde satisfatoriamente foi respondido que sim, tendo 
apenas um entrevistado justificando que pelo fato de ter assumido recentemente a secretaria não tinha uma opinião formada.

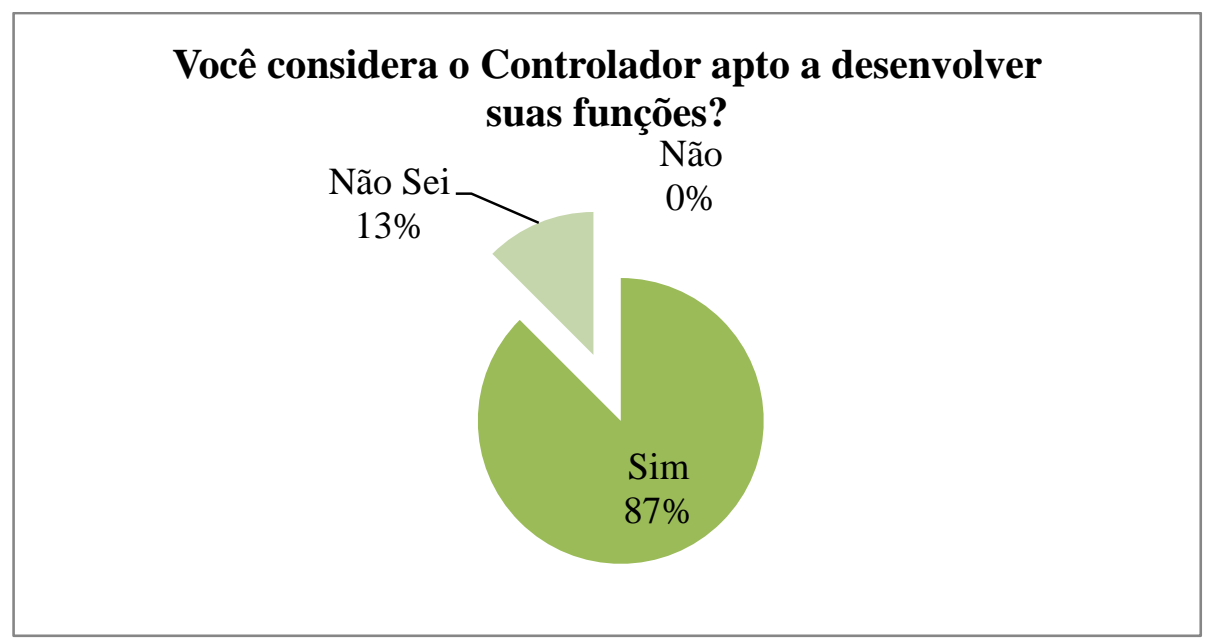

Fonte: elaborado pelos autores

Quando questionados sobre a aptidão do controlador para desenvolver suas funções, observa-se que na visão dos entrevistados, o mesmo encontra-se apto. Porém dentro desse contexto, necessário se faz esclarecer quais os conhecimentos e condutas de um controlador que o torna apto para conduzir suas atividades.

Oliveira et al (2002) ressaltam que para enfrentar os novos desafios o Controlador deve possuir diversas habilidades, como práticas internacionais de negócios, controles orçamentários e planejamento estratégico. Os autores ainda acrescentam que, para o desempenho da função de Controlador, os mesmos devem possuir conhecimentos de:

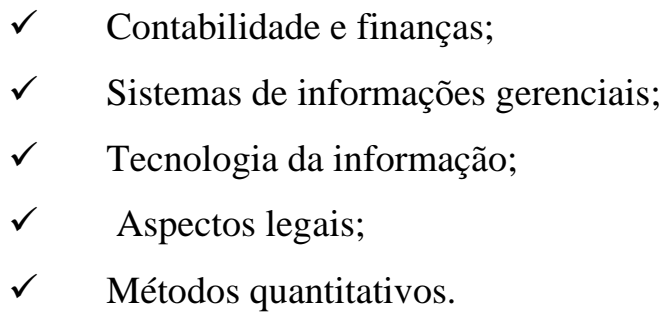

Tung (1980)diz que essas aptidões vão além da contabilidade, para o autor, o controlador deve possuir as seguintes habilidades:

Ter a capacidade de prever os problemas que poderão surgir e de coletar as informações necessárias para as tomadas de decisão; Elaboração de relatórios.Fornecer informações específicas a cada usuário.Elaborar relatórios de forma mais rápida possível, gerando informações atualizadas e confiáveis; Sempre que possível assumir a posição de conselheiro ou exercer 
o papel de consultor na busca de solução para os problemas, nunca a de crítico. TUNG (1980, p.85)

Oliveira et al (2002), enfatizam também que o controlador deve ser um profissional de fácil relacionamento e extremamente hábil para vender suas ideias. Tung (1980) acrescenta que:

O controller é, antes de tudo, um executivo de staff cuja função principal é obter e interpretar os dados que possam ser úteis aos executivos na formulação de uma nova política empresarial e, especialmente, na execução desta política. TUNG (1980, p.85)

Considerado um profissional da alta gestão, o controlador deve estar preparado e qualificado para atender as exigências do Tribunal de Contas e consequentemente as necessidades e dúvidas de todos os setores de uma prefeitura, para que estes possam atuar de acordo com as normas éticas e legais.

O Controlador deve possuir uma visão sistêmica da Administração Pública, dialogar com pessoas de diferentes áreas técnicas (importância do bom relacionamento interpessoal) e deter conhecimento amplo sobre Administração Pública, devem estar amparados legalmente para o exercício do cargo (provimentos efetivo) e possuir perfil, habilitação e deter prerrogativas específicas que lhe permitam o exercício de suas funções de forma satisfatória. (Cavalheiro e Flores, 2007).

No segundo momento, uma das perguntas foi "Como o Controle Interno o auxilia"? Em primeiro lugar das respostas aparece a observância das leis por parte dos gestores, pois como se sabe, a administração pública é regida por diversas legislações, e quando não observadas na consecução de alguma ação, causa inúmeros transtornos e diminui a credibilidade perante a sociedade.

Os gestores citaram também o setor como principal fonte de esclarecimentos, pois a qualquer momento pode-se entrar em contato com o controlador, que o mesmo os auxilia na melhor forma de desenvolver determinada atividade. 


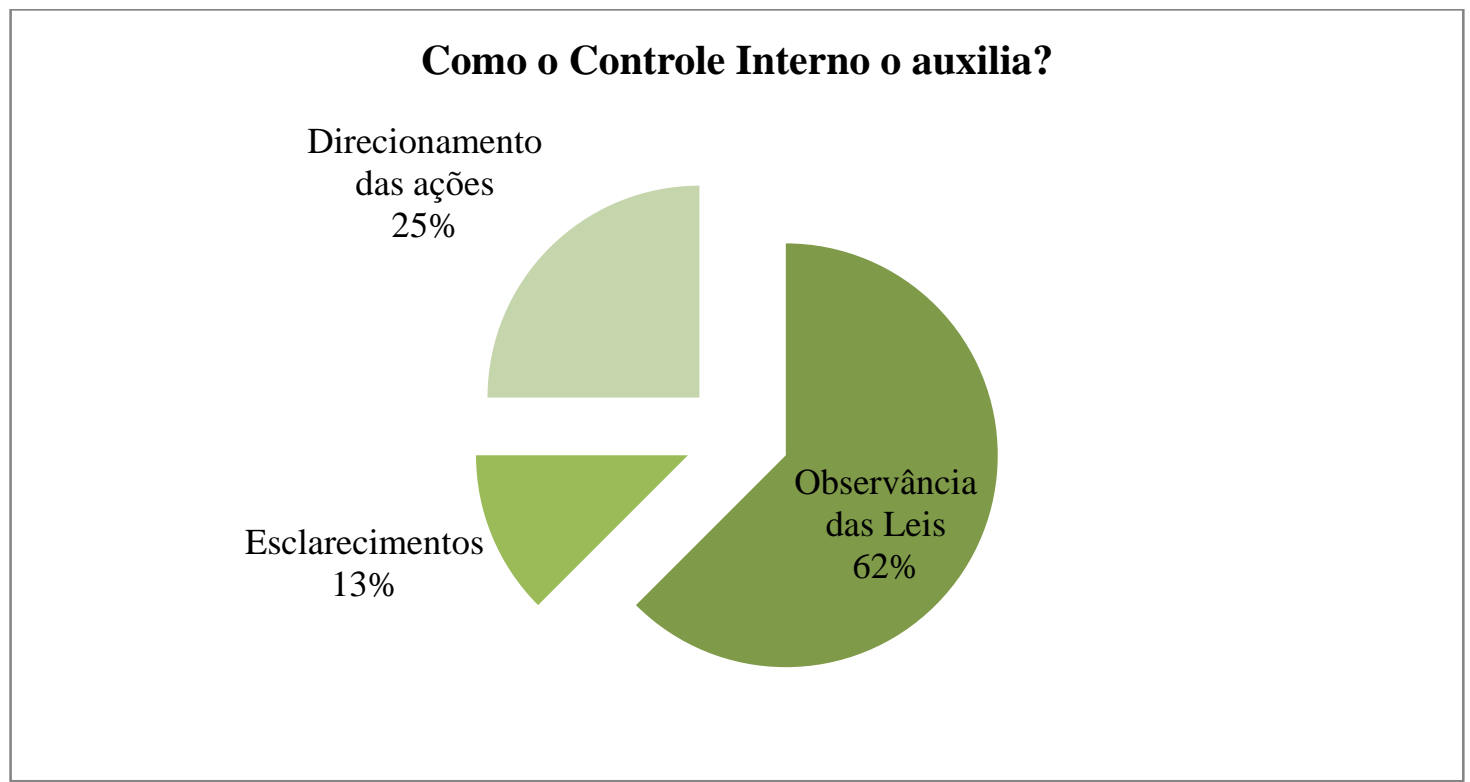

Fonte: elaborado pelos autores

Nakagawa (1993) diz que o controlador desempenha suas funções de maneira muito especial, e ao organizar e reportar dados relevantes exerce uma influência que induz os gerentes a tomarem decisões lógicas e consistentes com a missão e objetivos da empresa.

Visando saber dos gestores se estes já tomaram alguma decisão baseada nas informações e orientações do Controle Interno da prefeitura, as respostas foram que sim, e mais ainda, foram enfáticos em dizer que ficam mais seguros quando tomam decisões baseadas nas orientações do controlador, e que esta é a forma que todo setor de controle interno deve atuar, através de orientações, para que assim reduzam os altos índices de erros na administração pública.

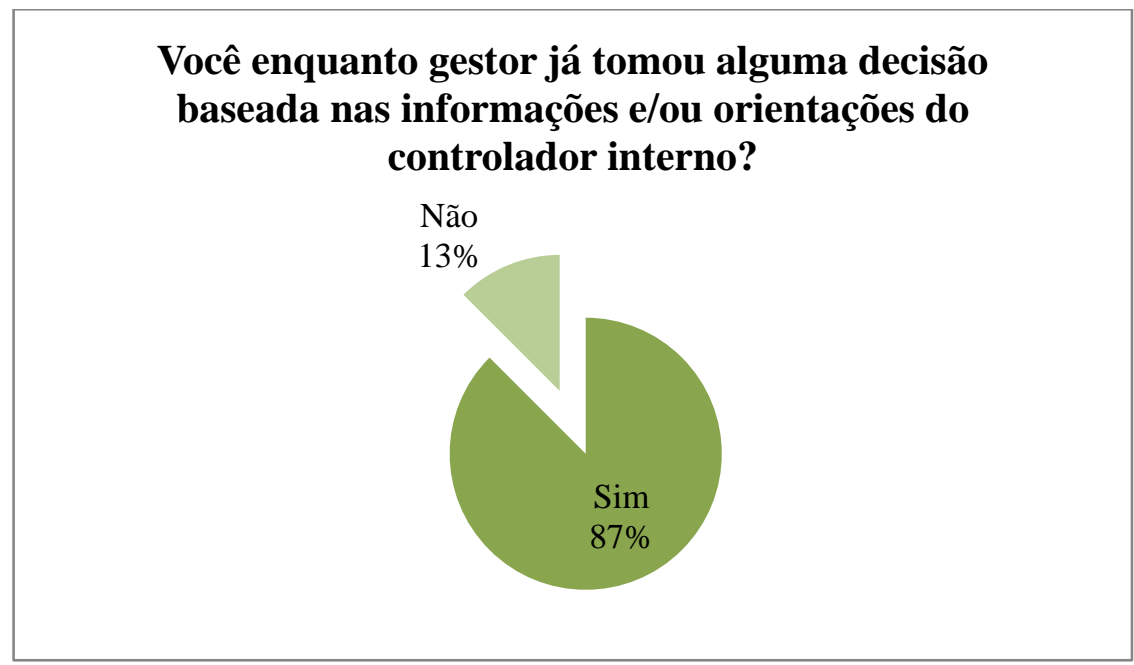

Fonte: elaborado pelos autores 
Como sugestões, os gestores disseram que o setor de Controle Interno deve divulgar mais o seu trabalho e o seu papel dentro da administração pública, auxiliando e proporcionando ao cidadão mais transparência, além de cursos que envolvam todos os gestores, pois assim os mesmos estarão sempre atualizados e colaborando com o desenvolvimento do município de Confresa-MT.

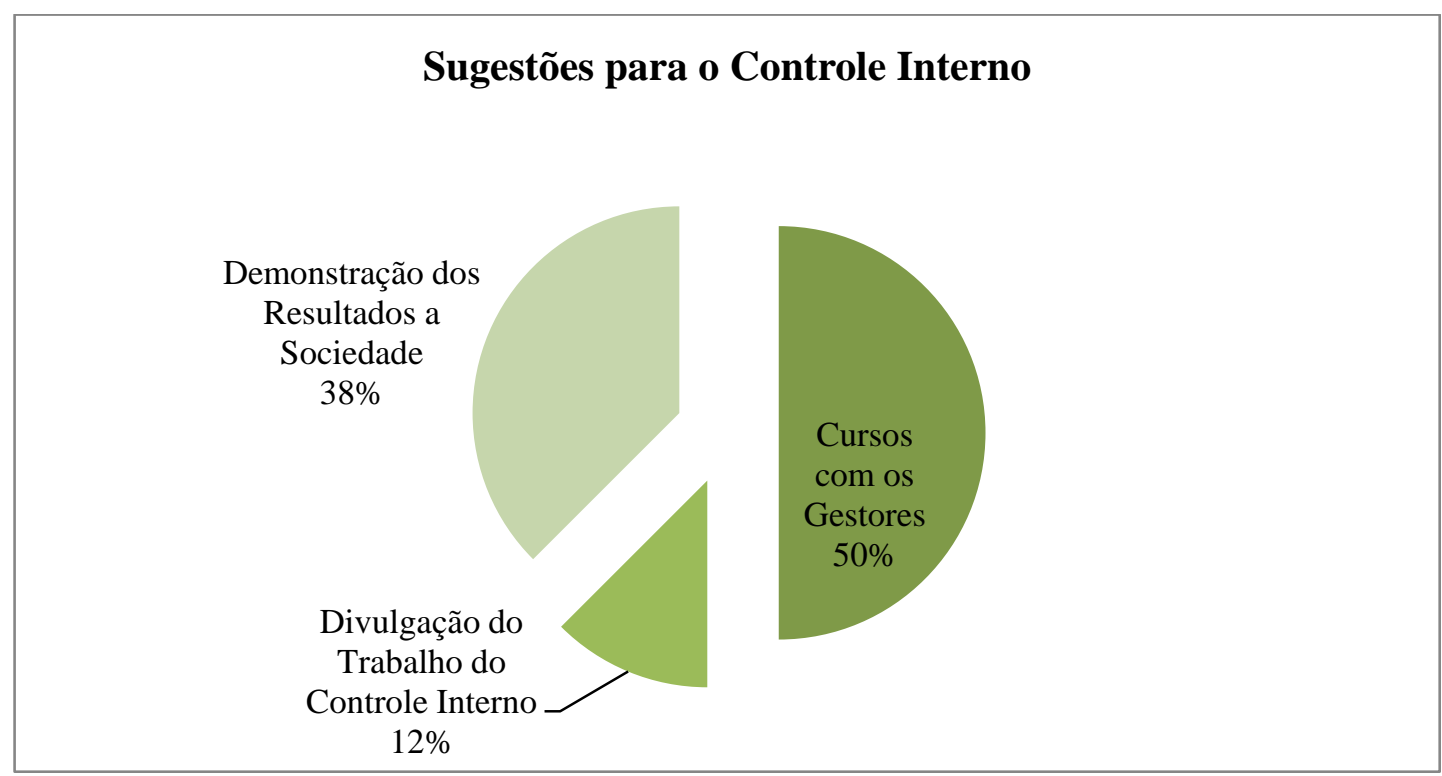

Fonte: elaborado pelos autores

Para Cavalheiro e Flores (2007), o controle interno pode ser considerado o instrumento mais eficaz, dentre todos, no combate à corrupção, evidenciando sua importância para o administrador, para a administração pública e para o interesse da sociedade. Conforme apontado pelos entrevistados, a realização de cursos com gestores aumentaria a percepção dos mesmos quanto à importância desse setor em uma prefeitura, assim como a disseminação de informações. Outro ponto relevante é a demonstração dos resultados a sociedade, divulgando a transparência na qual estão pautadas as ações do município.

Ao término da pesquisa e diante do exposto, algumas conclusões podem ser tomadas; os resultados apontam que todos os pesquisados estão satisfeitos com o auxilio e orientações do controlador, e afirmam que mantêm uma boa relação com o mesmo, o que contribui mais ainda para o bom desenvolvimento dos trabalhos.

Conforme apontado na pesquisa, o setor foi implantado em 2007, ou seja, já está consolidado quanto as atribuições básicas de orientação e auxílio na tomada de decisão, 
conforme ratificado nas falas dos entrevistados, onde relatam que buscam e utilizam as informações oriundas do Controle Interno.

Em qualquer organização, o controle interno é um instrumento fundamental, é através dessa ferramenta que os gestores acompanham o que está sendo realizado, garantindo maior confiabilidade dos relatórios financeiros, operacionais e contábeis, promovendo a efetividade das operações e instigando a obediência às políticas públicas da Administração Pública, além servir como ferramenta de orientação para as tomadas de decisões.

\section{CONSIDERAÇÕES FINAIS}

De modo geral, a função do Controle Interno, seja na iniciativa privada ou nos órgãos públicos estão voltadas a uma atuação preventiva quanto às possíveis falhas que possam prejudicar ou mesmo denegrir essa instituição junto à sociedade e de orientação quanto a gestão e consecução de seus objetivos e finalidades.

Percebe-se que o município estudado apresenta um Controle Interno estruturado e consolidado, apto a auxiliar seus gestores, o mesmo foi implantado em 2007, e até a presente data percorreu todas as fases de implantação e desenvolvimento de suas atividades.

Apesar de não ser realidade em muitos municípios brasileiros, a experiência de implantação do Controle Interno vêm se difundindo a cada ano e a perspectiva é que ocorram maiores avanços. Pesquisas apontam que ainda é necessário promover ajustes, assim como qualificar os profissionais controladores para que possam conduzir e desempenhar de forma eficiente suas funções.

Um sistema de controle interno efetivo e atuante, com um profissional apto, minimiza a ocorrência de fraudes e corrupção no sistema de gestão pública e ainda mais, direciona as ações dos gestores conforme a legislação, garantido transparência e correta aplicação dos recursos públicos.

Analisando a visão dos gestores percebe-se quão importante é o controle interno para o direcionamento e auxílio nos órgãos públicos, em específico nos municípios. O resultado da pesquisa ratifica o que é proposto através do controle interno, ou seja, auxiliar e direcionar as ações dos gestores para que ocorra em observância a normas legais, assim como garantir a transparência e excelência do gasto público. 
Para estudos futuros sugere-se investigar junto ao controlador quais as dificuldades que o mesmo encontra no desempenho de suas funções, para que assim se possa analisar as duas vertentes do Controle Interno.

\section{REFERÊNCIAS}

ATTIE, W. Auditoria Interna. 2 ed. São Paulo: Atlas, 2007.

BARDIN, L. Análise de conteúdo. Lisboa: Edições 70, 2010.

BEUREN, Ilse Maria. Como elaborar trabalhos monográficos: teoria e prática. 2. ed. São Paulo: Atlas, 2004.

BRASIL. Constituição Federal 1988. Brasília, DF: Senado, 1988.

BRASIL. Congresso Nacional (2000). Lei Complementar $n^{\circ}$ 101, de 04 de maio 2000. LRF - Lei de Responsabilidade Fiscal, Brasília, DF, 2000.

CAVALHEIRO, Jader Branco e FLORES, Paulo Cesar, A Organização do Sistema de Controle Interno Municipal, CRC - RG e ATRICON, Porto Alegre - RS, 2007.

CHIAVENATO. Adalberto. Comportamento Organizacional: a dinâmica do sucesso das organizações. Rio de Janeiro: Elsevier. 2005.

CRUZ, F. GLOCK, J.O. Controle Interno nos Municípios: orientações para a Implantação e Relacionamento com os Tribunais de Contas. 2.ed - São Paulo: Atlas, 2006.

DAMASCENA. Luzivalda Guedes. SOUZA. Cristiane de Oliveira. O Controle Interno na Gestão Pública Municipal: Estudo de caso na Prefeitura de Itaporanga - PB. Disponível em:<http://portal.virtual.ufpb.br/bibliotecavirtual/files/o_controle_interno_na_gestao_pablica _municipal_estudo_de_caso_na_prefeitura_de_itaporanga_a_pb_1343917431.pdf $>$. Acesso em 26 Jul. 2014.

Finalidade do Controle Interno. Disponível em: <www.tc.df.gov.br/contaspublicas/ice5/.../Arq04_Controles_Internos.pdf $>$. Acesso em: 15 Jul. 2014.

GIL.Antônio Carlos. Métodos e técnicas de pesquisa social. 5. ed.São Paulo: Atlas, 2007.

INTOSAI. Guidelines for Internal Controls Standards for the Public Sector 2004.Tradução de Cristina Maria Cunha Guerreiro, Delanise Costa e Soraia de Oliveira Ruther. Salvador: Tribunal de Contas do Estado da Bahia, 2007.

LEITE. Pedro Bezerra. MARTINS. Alexandre Lyra. O Controle Interno do município de Santana dos Garrotes - PB. Trabalho de conclusão de Curso. Universidade Aberta do Brasil, 2011. 
MARION, José Carlos; DIAS, Reinaldo; TRALDI, Maria Cristina; MARION, Márcia Maria Costa. Monografia para os cursos de administração, contabilidade e economia. 2. ed.São Paulo: Atlas, 2010.

MATO GROSSO. Tribunal de Contas do Estado. Guia para implantação do Sistema de Controle Interno na administração pública / Tribunal de Contas do Estado - . Cuiabá: TCE 2007.

MEIRELLES, Hely Lopes. Direito municipal brasileiro. 15.Ed. São Paulo:Malheiros, 2006. NAKAGAWA. Masayuki. Estudo de alguns aspectos de Controladoria que contribuem para a eficácia gerencial. 1987. Tese de doutorado. FEA-USP, São Paulo.

OLIVEIRA, Luis Martins; PEREZ, Jr.; José Hernandez, SILVA; Carlos Alberto dos Santos. Controladoria Estratégica. São Paulo: Atlas, 2002.

PELEIAS, I. R. Falando sobre o sistema de controle interno. Boletim IOB 192- Temática Contábil e Balanços, São Paulo, n. 37, 2003.

PEREIRA. Regina Giannetti d.5 Pilares do Relacionamento Interpessoal no Trabalho. Disponível em: http://www.academiadopalestrante.com.br/artigos/5-pilares-dorelacionamento-interpessoal-no-trabalho. Acesso em: 14 set. 2014.

QUEIROZ. Edna Câmara de Miranda. Controle interno e auditoria interna como instrumento de apoio para gestão de empresas. Disponível em: <http://www.cpgls.ucg.br/ArquivosUpload/1/File/CPGLS/IV\%20MOSTRA/NEGCIO/Contro le $\% 20$ interno $\% 20 \mathrm{e} \% 20$ auditoria $\% 20$ interna $\% 20$ como $\% 20$ Instrumento $\% 20 \mathrm{de} \% 20$ apoio $\% 20 \mathrm{p}$ ara\%20gesto.pdf>. Acesso em 27 Jul. 2014.

TUNG. Nguyen. H. Controladoria Financeira das Empresas: uma abordagem prática. 6. ed. São Paulo: Edusp, 1980. 